\title{
Fatores de risco em contatos intradomiciliares de pacientes com hanseníase utilizando variáveis clínicas, sociodemográficas e laboratoriais
}

\section{Risk factors in household contacts of leprosy patients using clinical, sociodemographic, and laboratorial variables}

Maria Heliana Chaves Monteiro da Cunha', Maria do Perpétuo Socorro Amador Silvestre ${ }^{2}$, Alison Ramos da Silva ${ }^{3}$, Diana Domingas Silva do Rosário ${ }^{4}$, Marília Brasil Xavier ${ }^{3}$

' Universidade Federal do Pará, Instituto de Ciências da Saúde, Faculdade de Enfermagem, Belém, Pará, Brasil

2 Instituto Evandro Chagas/SVS/MS, Seção de Bacteriologia e Micologia, Laboratório de Hanseníase, Ananindeua, Pará, Brasil

${ }^{3}$ Universidade Federal do Pará, Laboratório de Pesquisas em Epidemiologia Tropical e Doenças Endêmicas, Belém, Pará, Brasil

${ }^{4}$ Universidade Federal do Pará, Belém, Pará, Brasil

\begin{abstract}
RESUMO
OBJETIVO: Identificar fatores de risco em contatos intradomiciliares de pacientes com hanseníase, utilizando-se variáveis clínicas, sociodemográficas e laboratoriais. MATERIAIS E MÉTODOS: Investigou-se uma série de casos, avaliando-se contatos intradomiciliares de pacientes com hanseníase, atendidos em um centro de referência do estado do Pará, Brasil, no período de 2012 a 2015. Foram realizados os exames dermatoneurológico, sorologia anti-PGL-I (ELISA, utilizando pontos de corte 0,2 e 0,13 ) e o controle da vacina BCG, além de ter sido elaborado levantamento de dados clínicos e demográficos do caso índice. RESULTADOS: Ocorreu maior predominância de contatos com pelo menos uma dose vacinal de BCG $(91,1 \%)$, e houve maior soropositividade entre contatos das formas de hanseníase multibacilar, sendo mais prevalente quando utilizado o ponto de corte 0,13 (61,5\%). As maiores titulações de anti-PGL-I ocorreram entre pessoas do sexo feminino $(51,1 \%)$, com ensino fundamental $(46,7 \%)$ e na faixa etária de 15 a 40 anos $(47,8 \%)$. A maioria dos indivíduos $(91,4 \%)$ habitava casas com menos de dois cômodos. CONCLUSÃO: Concluiu-se que baixa escolaridade, idade e condições de moradia podem ser fatores de risco para o adoecimento por hanseníase entre os contatos intradomiciliares das formas multibacilares; que as faixas etárias mais jovens estão mais expostas ao contato com o bacilo da hanseníase; e que a sorologia anti-PGL-I é uma importante ferramenta de seguimentos de contatos das formas multibacilares.
\end{abstract}

Palavras-chave: Hanseníase; Vigilância Epidemiológica; Sorologia; Fatores de Risco.

\begin{abstract}
OBJECTIVE: To identify risk factors in household contacts of leprosy patients, using clinical, sociodemographic, and laboratorial variables. MATERIALS AND METHODS: Cases series were investigated evaluating the household contacts of leprosy patients that were attended in a reference center in Pará State, Brazil, from 2012 to 2015. Dermatoneurological examinations, anti-PGL-I serology (ELISA, using cut-off point 0.2 and 0.13 ), and BCG vaccine control were performed, as well as clinical demographic data survey from the index case was conducted. RESULTS: There was higher predominance of the contacts that had been BCG vaccinated at least once (91.1\%), higher seropositivity among contacts that present the disease multibacillary leprosy form, being more prevalent when the cut-off point was 0.13 (61.5\%). The higest anti-PGL-I titrations were detected among the female group (51.1\%), those that had elementary education (46.7\%) and were among 15 to 40 years old $(47.8 \%)$. The majority of individuals (91.4\%) lived in houses with less than two rooms. CONCLUSION: It was concluded that low education level, age and living conditions may be risk factors for leprosy illness among household contacts of the multibacillary leprosy form; the younger age groups are more exposed to the bacillus contact; and that the anti-PGL-I serology is an important tool for tracking contacts of multibacillary leprosy forms.
\end{abstract}

Keywords: Leprosy; Epidemiological Surveillance; Serology; Risk Factors.

\author{
Correspondência / Correspondence: \\ Maria Heliana Chaves Monteiro da Cunha \\ Trav. Angustura, 1829. Bairro: Pedreira - CEP: 66080-180 - Belém, Pará, Brasil \\ E-mail: marjo.familia@hotmail.com
}




\section{INTRODUÇÃO}

A hanseníase é uma doença com capacidade de produzir, em seus portadores, lesões dermatológicas e perda das sensibilidades térmica, dolorosa e tátil e, quando não tratada, pode levar ao desenvolvimento de incapacidades. É causada pelo Mycobacterium leprae, um bacilo com afinidade pelas células de Schwann do sistema nervoso periférico ${ }^{1}$. Pode incidir em todos os indivíduos, independentemente de idade e sexo. No entanto, observa-se maior prevalência nas classes sociais economicamente menos favorecidas e em indivíduos com caso de hanseníase na família, o que indica que o contato íntimo e prolongado favorece a transmissão².

A Organização Mundial da Saúde classifica a hanseníase, quanto ao esquema terapêutico, em paucibacilar (PB) e multibacilar (MB), sendo essa última a forma infectante ${ }^{3}$. A clínica, segundo a classificação de Madri, divide as formas de hanseníase em indeterminada (MHI), tuberculoide (MHT), dimorfa (MHD) e virchowiana (MHV), sendo as duas últimas correspondentes à forma $M B$ e, consequentemente, infectantes ${ }^{4}$.

Por ter uma evolução lenta e silenciosa, em geral, é diagnosticada quando o paciente já se encontra em estágio avançado, apresentando incapacidades e favorecendo a continuidade no elo de transmissão da doença, dificultando sua vigilância e controle. As recomendações do Ministério da Saúde contribuem para a redução dos indicadores epidemiológicos da hanseníase, pois envolvem a descoberta de casos novos por meio da detecção de contatos intradomiciliares e o uso da vacina BCG em contatos intradomiciliares sem sinais clínicos da doença, independentemente da forma clínica do caso índice ${ }^{5}$.

contato ou comunicante é aquele que convive ou conviveu com um doente com hanseníase nos últimos cinco anos, antes de esse iniciar o tratamento ${ }^{6}$. Esse grupo precisa que ações de controle lhes sejam direcionadas, iá que a probabilidade de adoecer é maior, sendo o risco de quatro a 10 vezes maior quando houver contato com paciente MB. $O$ controle visa diagnosticar precocemente novos casos e tratálos antes que continuem com a cadeia de transmissão, bem como prevenir incapacidades ${ }^{7}$.

A identificação do glicolipídeo fenólico-I (PGL-I), antígeno específico do $M$. leprae, abriu novas possibilidades para a identificação de infecção subclínica entre os comunicantes. A carga de anticorpos anti-PGL-I é comumente maior na forma $M B$, sendo facilmente identificada. Entretanto, níveis detectáveis podem ser encontrados em indivíduos assintomáticos, principalmente quando esses são comunicantes de casos $\mathrm{MB}^{8,9}$. Entre as ferramentas utilizadas para identificação do PGL-I, destaca-se a sorologia pelo método ELISA, que, aliada aos testes de sensibilidade, força e inspeção de troncos nervosos, auxilia na identificação de indivíduos com risco aumentado de desenvolver a doença entre os comunicantes $^{10,11}$. controle epidemiológico da hanseníase em contatos intradomiciliares, com base em fatores de risco, utilizando variáveis clínicas, sociodemográficas e laboratoriais, é de suma importância, no sentido de se averiguarem comunicantes com maior risco de adoecer e possíveis casos de infecção subclínica. Dessa maneira, o objetivo do presente trabalho foi identificar fatores de risco para o desenvolvimento da hanseníase entre os contatos intradomiciliares de casos de hanseníase residentes em área endêmica, em tratamento em ambulatório especializado para a doença.

\section{MATERIAIS E MÉTODOS}

Trata-se de estudo descritivo transversal, do tipo série de casos, que avaliou, de 2014 a 2015, contatos intradomiciliares de pacientes com hanseníase atendidos em um centro de referência para atendimento à doença no período de 2012 a 2015.

$\bigcirc$ estudo foi realizado no ambulatório do Núcleo de Medicina Tropical da Universidade Federal do Pará (NMT/UFPA), referência no estado do Pará para tratamento de casos de hanseníase e outras doenças tropicais. Durante o período de levantamento dos pacientes com hanseníase, verificou-se que foram atendidos 82 casos no NMT/UFPA, estimando-se um total médio de 205 comunicantes (três comunicantes para um paciente). Contudo, apenas 36 casos índices contatados compareceram à avaliação, perfazendo um total de 90 pessoas. A pesquisa foi dividida em cinco etapas:

Etapa 1 - Foi realizado, em março de 2014, o levantamento dos casos de hanseníase nos prontuários dos pacientes que realizaram tratamento nos anos de 2012 a 2015 no NMT/UFPA, seguido de convocação e agendamento de seus respectivos comunicantes intradomiciliares, por meio de contato telefônico.

Etapa 2 - Nos dias agendados, os comunicantes eram acolhidos (quatro comunicantes em duas vezes na semana), recebendo esclarecimentos básicos a respeito da doença e da necessidade da realização do controle epidemiológico da hanseníase em área endêmica. A ação educativa era realizada em rodas de conversa, utilizando-se linguagem acessível e recurso multimídia com figuras ilustrativas sobre as formas clínicas da doença, havendo controle epidemiológico da hanseníase e entrega de fôlderes sobre prevenção, manifestações clínicas e tratamento.

Etapa 3 - Após a ação educativa, era realizada, individualmente, a coleta de dados em uma ficha protocolo elaborada para essa finalidade, com informações referentes ao caso índice (forma clínica, data do início do tratamento, esquema terapêutico, história de hanseníase na família) e ao comunicante, contendo perguntas com variáveis clínicas (avaliação dermatoneurológica, controle da vacina BCG) e sociodemográficas. Posteriormente, era realizada a avaliação dermatoneurológica dos comunicantes e testes de sensibilidade térmica, dolorosa e tátil na ocorrência de lesões suspeitas e palpação dos nervos 
periféricos $^{10}$. Na ausência de uma das sensibilidades e presença de espessamento de um ou mais nervos, o comunicante era encaminhado para avaliação com dermatologista. Na presença de lesões não suspeitas de hanseníase (outras dermatoses), também havia encaminhamento para avaliação dermatológica e tratamento, se necessário. Avaliou-se, também, a presença da cicatriz vacinal de BCG. Na ausência dessa cicatriz, associada à ausência de lesões suspeitas, o procedimento adotado, conforme as normas do Ministério da Saúde ${ }^{5}$, era o encaminhamento do comunicante para recebimento da dose da vacina BCG.

Etapa 4 - Para realizar a sorologia anti-PGL-I, procedeu-se à retirada de $5 \mathrm{~mL}$ de sangue periférico de cada comunicante, utilizando-se sistema de coleta a vácuo sem anticoagulante, após adequada antissepsia do local. $\bigcirc$ sangue foi centrifugado a $1.500 \mathrm{rpm} / 10 \mathrm{~min}$ em centrífuga calibrada, e o soro foi acondicionado em tubos criogênicos a $-20{ }^{\circ} \mathrm{C}$.

Etapa 5 - $\bigcirc$ material biológico centrifugado foi colocado em caixas isotérmicas a $4{ }^{\circ} \mathrm{C}$ e transportado, por via terrestre, para o Instituto Evandro Chagas (IEC), onde foi realizada a pesquisa de anticorpos $\lg M$ contra o antígeno PGL-I do M. leprae por meio do método ELISA in house, utilizando-se protocolo previamente estabelecido ${ }^{8}$. Foi empregado o antígeno semissintético NT-P-BSA. Para indicar a positividade, foram adotados pontos de corte $(P C)=0,2$ e 0,1312. Todos os soros foram testados em duplicata e os resultados de ELISA foram expressos pela média do valor final da densidade óptica de cada amostra.

Foram excluídos do estudo os comunicantes de casos índices com alguma coinfecção, os menores de 7 anos de idade, os que faltaram em mais de quatro agendamentos consecutivos e os que se recusaram a participar de todas as etapas da pesquisa ou a assinar o Termo de Consentimento Livre e Esclarecido.

Os dados foram armazenados em banco de dados elaborado no programa Microsoft Excel ${ }^{\circledR} 2007$, e as análises foram realizadas no programa BioEstat v5.3 $3^{13}$, considerando-se o intervalo de confiança de 95\% e nível $\alpha$ de $5 \%$ ( $p \leq 0,05)$. Foram realizadas medidas de tendência central, teste $t$ de Student para comparação entre variáveis e correlação linear de Pearson para avaliar a relação entre idade e titulação de anti-PGL-I.

$\bigcirc$ presente estudo cumpriu as normas estabelecidas pela Resolução n 466/12 do Conselho Nacional de Saúde, tendo sido submetido ao Comitê de Ética em Pesquisa em Seres Humanos do NMT/UFPA e aprovado segundo parecer $n^{\circ} 525.515$ em 13 de fevereiro de 2014.

\section{RESULTADOS}

Entre os casos índices que fizeram parte do estudo, observou-se que a forma clínica mais diagnosticada, segundo a classificação de Madri, foi a MHD, com 44,5\% (16/36), seguida de MHI e MHT, com 22,2\% e 13,9\%, respectivamente (Tabela 1).
Tabela 1 - Distribuição dos casos de hanseníase segundo a forma clínica, Belém, estado do Pará, Brasil, 2012-2015

\begin{tabular}{lcc}
\hline Forma clínica & \multicolumn{3}{c}{ Casos índice } \\
& $N$ & $\%$ \\
\hline MHI & 8 & 22,2 \\
MHT & 5 & 13,9 \\
MHD & 16 & 44,5 \\
MHV & 4 & 11,1 \\
Neural pura & 3 & 8,3 \\
\hline Total & 36 & 100,0 \\
\hline
\end{tabular}

O perfil sociodemográfico dos comunicantes identificou que $47,8 \%$ (43/90) pertenciam à faixa etária de 15 a 39 anos, seguida por uma faixa de menores de 15 anos, com percentual de 24,5\% $(22 / 90)$. A maioria possuía ensino fundamental (46,7\%; 42/90), era oriunda da Região Metropolitana de Belém (93,3\%; 84/90), tinha estado civil "solteiro" (43,3\%; 39/90), pertencia ao sexo feminino $(51,1 \%$; 46/90) e possuía renda per capita superior a R\$ 400,00 (68,6\%; 24/35). Em relação ao número de cômodos da moradia, a maioria dos indivíduos $(91,4 \% ; 32 / 35)$ disse habitar casas com menos de dois cômodos (Tabela 2).

A avaliação clínica realizada nos comunicantes mostrou que a maioria deles não apresentava qualquer tipo de lesão no corpo sugestiva de hanseníase, correspondendo a 80,0\% (72/90). A maioria dos comunicantes, 91,1\% (82/90), apresentava cicatriz da vacina BCG (Tabela 2 ).

Quanto à soropositividade do teste ELISA entre os comunicantes, utilizando-se PC de 0,13 e 0,2, e sua relação com a forma clínica dos casos índices, 13 comunicantes foram positivos, $\operatorname{com} P C=0,13$, segundo a classificação de Madri, sendo que $38,4 \%$ tinham como caso índice portadores de hanseníase MB (MHD). Houve quatro indivíduos positivos para $P C=0,2$, segundo a classificação operacional, sendo dois com caso índice $\mathrm{PB}$ $(50,0 \%)$ e dois com caso índice MB (50,0\%) (Tabela 3).

Quanto às titulações de anti-PGL-I dos comunicantes, observou-se aumento dos títulos de maneira inversamente proporcional à escolaridade (Figura 1), discreta aproximação do $P C=0,13$ quando avaliado 0 sexo feminino (Figura 2) e maior média nos não vacinados com BCG (Figura 3).

A correlação não demonstrou tendência significativa do aumento dos níveis de PGL-I com a diminuição ou aumento da idade $(r=0,0561)$, embora as maiores titulações tenham sido observadas nas faixas etárias abaixo dos 40 anos (Figura 4). 
Tabela 2 - Características sociodemográficas e clínicas dos comunicantes intradomiciliares de casos de hanseníase, Belém, estado do Pará, Brasil, 2012-2015

\begin{tabular}{|c|c|c|}
\hline \multicolumn{3}{|c|}{ Comunicantes intradomiciliares } \\
\hline & $\mathrm{N}$ & $\%$ \\
\hline \multicolumn{3}{|l|}{ Idade (anos) } \\
\hline$<15$ & 22 & 24,5 \\
\hline $15-39$ & 43 & 47,8 \\
\hline $40-60$ & 21 & 23,3 \\
\hline$>60$ & 4 & 4,4 \\
\hline Total & 90 & 100,0 \\
\hline \multicolumn{3}{|l|}{ Escolaridade } \\
\hline Ensino fundamental & 42 & 46,7 \\
\hline Ensino médio & 39 & 43,3 \\
\hline Ensino superior & 9 & 10,0 \\
\hline Total & 90 & 100,0 \\
\hline \multicolumn{3}{|l|}{ Procedência } \\
\hline Região Metropolitana de Belém & 84 & 93,3 \\
\hline Interior do Pará & 2 & 2,2 \\
\hline Região das ilhas* & 4 & 4,5 \\
\hline Total & 90 & 100,0 \\
\hline \multicolumn{3}{|l|}{ Estado civil } \\
\hline Solteiro & 39 & 43,3 \\
\hline Casado & 31 & 34,5 \\
\hline Divorciado & 1 & 1,1 \\
\hline Viúvo & 4 & 4,4 \\
\hline União estável & 15 & 16,7 \\
\hline Total & 90 & 100,0 \\
\hline \multicolumn{3}{|l|}{ Sexo } \\
\hline Masculino & 44 & 48,9 \\
\hline Feminino & 46 & 51,1 \\
\hline Total & 90 & 100,0 \\
\hline \multicolumn{3}{|c|}{ Quantidade de cômodos por residência } \\
\hline$<2$ & 32 & 91,4 \\
\hline $2-4$ & 3 & 8,6 \\
\hline$>5$ & - & - \\
\hline Total & $35^{\dagger}$ & 100,0 \\
\hline \multicolumn{3}{|l|}{ Renda mensal por residência (R\$) } \\
\hline$<100,00$ & - & - \\
\hline $100,00-400,00$ & 11 & 31,4 \\
\hline$>400,00$ & 24 & 68,6 \\
\hline Total & $35^{\dagger}$ & 100,0 \\
\hline \multicolumn{3}{|l|}{ Situação vacinal } \\
\hline Sem cicatriz & 8 & 8,9 \\
\hline Com cicatriz & 82 & 91,1 \\
\hline Total & 90 & 100,0 \\
\hline \multicolumn{3}{|l|}{$\begin{array}{l}\text { Manifestações clínicas suspeitas de } \\
\text { hanseníase }\end{array}$} \\
\hline Presente & 18 & 20,0 \\
\hline Ausente & 72 & 80,0 \\
\hline Total & 90 & 100,0 \\
\hline
\end{tabular}

* A região das ilhas corresponde à área insular da Região Metropolitana de Belém; † $O$ número de índices caiu de 36 para 35, em virtude de um deles residir na mesma casa; Sinal convencional utilizado: - Dado numérico igual a zero não resultante de arredondamento.
Tabela 3 - Soropositividade anti-PGL-I (ELISA) nos comunicantes segundo a forma clínica do caso índice, Belém, estado do Pará, Brasil, 2012-2015

\begin{tabular}{|c|c|c|c|c|}
\hline \multirow[t]{2}{*}{ Classificação } & \multicolumn{2}{|c|}{$\begin{array}{l}\text { Soropositividade } \\
\qquad P C=0,13\end{array}$} & \multicolumn{2}{|c|}{$\begin{array}{c}\text { Soropositividade } \\
\quad P C=0,2\end{array}$} \\
\hline & $N$ & $\%$ & $\mathrm{~N}$ & $\%$ \\
\hline \multicolumn{5}{|l|}{ Madri } \\
\hline $\mathrm{MHI}$ & 2 & 15,4 & - & - \\
\hline MHT & 3 & 23,1 & 2 & 50,0 \\
\hline MHD & 5 & 38,4 & - & - \\
\hline MHV & 2 & 15,4 & 1 & 25,0 \\
\hline Neural pura & 1 & 7,7 & 1 & 25,0 \\
\hline Total & 13 & 100,0 & 4 & 100,0 \\
\hline \multicolumn{5}{|l|}{ Operacional } \\
\hline PB & 5 & 38,5 & 2 & 50,0 \\
\hline$M B$ & 8 & 61,5 & 2 & 50,0 \\
\hline Total & 13 & 100,0 & 4 & 100,0 \\
\hline
\end{tabular}
resultante de arredondamento.

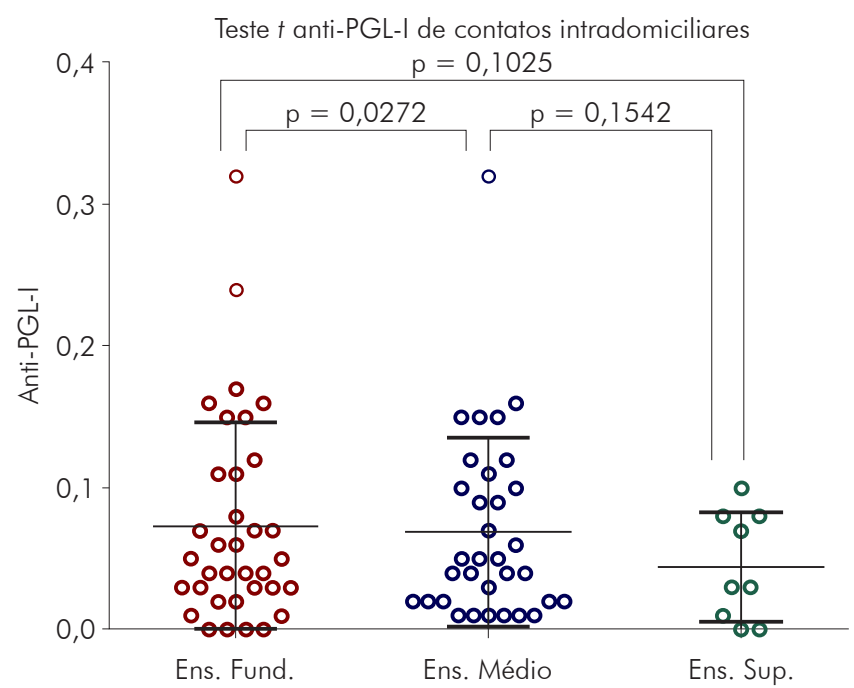

Figura 1 - Média dos níveis de anti-PGL-I dos comunicantes segundo escolaridade, Belém, estado do Pará, Brasil, 2012-2015

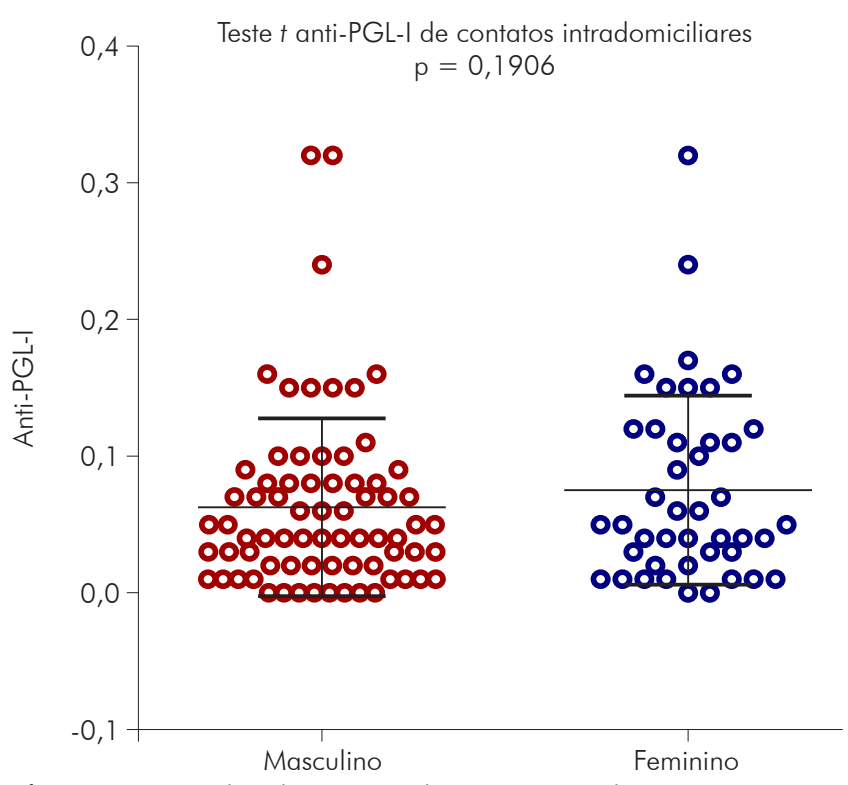

Figura 2 - Média dos níveis de anti-PGL-I dos comunicantes segundo o sexo, Belém, estado do Pará, Brasil, 2012-2015 


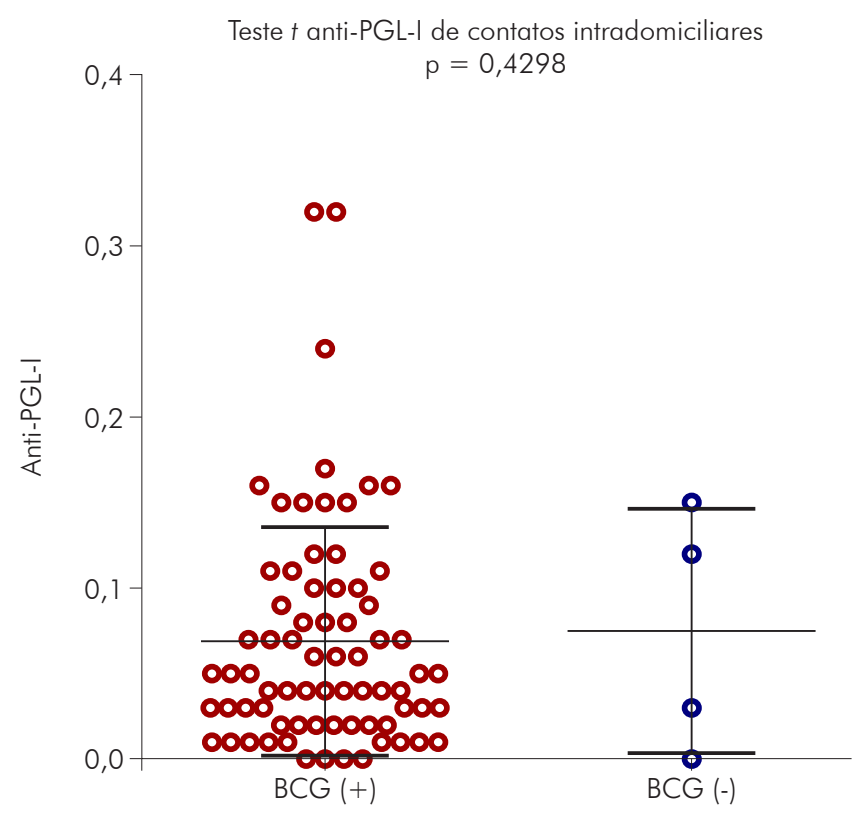

Figura 3 - Média dos níveis de anti-PGL-I dos comunicantes segundo vacina BCG, Belém, estado do Pará, Brasil, 2012-2015

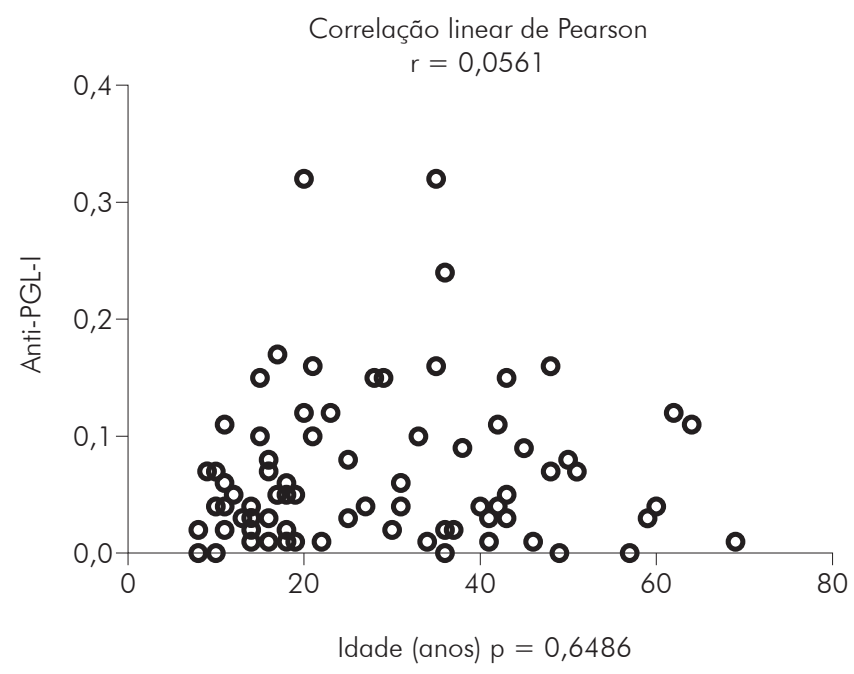

Figura 4 - Correlação dos níveis de anti-PGL-I segundo densidade óptica e idade dos comunicantes, Belém, estado do Pará, Brasil, 2012-2015

\section{DISCUSSÃO}

O perfil dos casos índices deste estudo demonstrou que a predominância da forma contaminante foi a MHD, segundo a classificação de Madri, e MB, segundo a classificação operacional, concordando com pesquisas que afirmam serem as formas $M B$ as contaminantes e responsáveis por manterem o foco da doença ${ }^{14}$. O Ministério da Saúde afirma que os contatos de doentes MB devem ser acompanhados por cinco anos, pelo fato do período de incubação do bacilo ser longo e ser maior o risco de adoecimento. No entanto, a vigilância também se estende aos contatos de doentes PB, mas por menor tempo, dois anos, em virtude do risco de contaminação ser menor ou praticamente inexistir, uma vez que se trata de forma não contaminante ${ }^{15}$. Além do exame anual realizado pelo profissional de saúde, a vigilância de contatos pode ser feita pelo próprio indivíduo por intermédio do autoexame, desde que esse seja bem orientado, devendo ocorrer em períodos semestrais.

perfil sociodemográfico dos comunicantes estudados mostrou que os indivíduos expostos ao $M$. leprae concentram-se na faixa etária considerada jovem e muito jovem. Adolescentes e jovens precocemente expostos podem desenvolver a doença em idade produtiva, em virtude do longo período de incubação ${ }^{16}$, fato esse que pode acarretar inúmeros transtornos pessoais e sociais ${ }^{17}$. Um estudo realizado em área endêmica na Amazônia brasileira também encontrou ○ mesmo perfil jovem entre os comunicantes ${ }^{18}$. Desse modo, reitera-se a necessidade da realização de novas avaliações dermatoneurológicas e de acompanhamento sorológico, principalmente em comunicantes de caso índice MB.

A escolaridade dos comunicantes deste estudo apresentou frequências maiores no ensino fundamental, e talvez esse fator seja um colaborador negativo para a dificuldade em se conseguir que os comunicantes compareçam para as avaliações e adquiram um entendimento melhor sobre sua importância epidemiológica no controle da doença. Um estudo com comunicantes de hanseníase, na área metropolitana de Belém, também observou a mesma dificuldade relacionada a esse fator ${ }^{19}$.

A distribuição dos comunicantes, segundo moradia e renda per capita mensal, identificou que a proporção de pessoas que habitavam residências com menos de dois cômodos foi maior, e que a maioria vivia com renda per capita mensal superior a $R \$ 400,00$. O Banco Nacional de Desenvolvimento Econômico e Social afirma que são consideradas populações em linha de pobreza aquelas que vivem com renda per capita equivalente ao de uma cesta básica, cujo valor, no estado do Pará, oscila em torno de $R \$ 300,00^{20}$. Com relação à habitação, o Instituto Brasileiro de Geografia e Estatística considera que uma família grande deve habitar uma casa de no mínimo três cômodos ${ }^{21}$. Desse modo, a maioria dos comunicantes deste estudo pode ser considerada vivendo na linha de pobreza e em moradia inadequada, fatores que, segundo o Ministério da Saúde ${ }^{6}$, propiciam a disseminação da hanseníase, sendo, portanto, fatores de risco.

Ao exame clínico, a grande maioria dos comunicantes não apresentou nenhum tipo de lesão na pele sugestiva de hanseníase. Esse tipo de achado pode ser atribuído ao pequeno número de comunicantes que fizeram parte do estudo. Entretanto, uma pesquisa realizada em Londrina, estado do Paraná, examinando 1.641 comunicantes, encontrou cerca de 180 indivíduos com lesões sugestivas de hanseníase ${ }^{17}$.

O alto número de pesquisados que apresentaram pelo menos uma cicatriz vacinal de BCG no braço direito constitui um achado satisfatório e importante epidemiologicamente para comunicantes de hanseníase; mas não corresponde ao ideal, uma vez que essa vacina foi incluída como medida de controle da hanseníase para uso em contatos de portadores das 
diversas formas de hanseníase, em duas doses ${ }^{5,15}$. 0 Brasil é o único país endêmico que adota a dose de reforço da vacina BCG como suporte para o sistema imunológico na luta contra a hanseníase, conduta adotada possivelmente pela baixa cobertura dos exames de contato $^{22}$.

Com relação ao comportamento sorológico anti-PGL-I utilizando dois PC $(0,13$ e 0,2$)$, a positividade encontrada pode sugerir a presença de infecção subclínica pelo $M$. leprae ${ }^{23}$, e, portanto, esses comunicantes devem ser avaliados clínica e laboratorialmente em intervalos mais curtos, principalmente os comunicantes de caso índice MB.

A soropositividade predominante nos comunicantes de casos índices MB concorda com as informações das notificações que chegam ao Sistema de Informação de Agravos de Notificação, nas quais predomina o diagnóstico de casos novos entre comunicantes de pacientes MB em Belém e Região Metropolitana ${ }^{24,25}$.

A análise da soropositividade anti-PGL-I, em relação à escolaridade, sugere que a baixa formação escolar tem como consequência menos informação e maior risco de contaminação por doenças, entre elas a hanseníase. A análise de níveis de soropositividade entre contatos e não contatos de portadores de hanseníase e escolares da população geral de um município do oeste do Pará, onde a endemicidade é alta e a escolaridade é baixa, encontrou percentuais de soropositividade elevados em todos os grupos. A positividade encontrada nos escolares levanta indícios de que existe uma elevada prevalência de infecção subclínica pelo $M$. leprae entre eles, e de que a origem do contato estaria em caso índice não identificado no domicílio dos escolares ${ }^{26}$.

A média dos níveis de anti-PGL-I referente ao sexo feminino apresentou discreta aproximação do $P C=0,13$, demonstrando maior soropositividade nesse grupo. Esse resultado é concordante com as pesquisas que afirmam que mulheres jovens e crianças têm, como característica natural do sistema imunológico, tendência em produzir maior quantidade de $\lg M$, que se traduziria em exame sorológico ELISA positivo, sem necessariamente estar associado à infecção subclínica pelo M. leprae ${ }^{27}$. Apesar de ser uma característica do sistema imunológico no sexo feminino jovem, é importante e necessário o seguimento desse grupo com tendência à soropositividade em áreas de elevada endemicidade para hanseníase.

A maior média dos níveis de anti-PGL-I nos indivíduos não vacinados demonstrou que existe uma tendência de elevação dos títulos desse antígeno nesse grupo, o que comprova ser a vacina uma grande aliada no controle da doença. A Organização Mundial da Saúde reafirma a importância da vacina BCG, criando uma norma para a administração da mesma de acordo com a história vacinal do contato, ficando dessa maneira a prescrição da vacina: em caso de incerteza de cicatriz vacinal, aplicar uma dose; sem cicatriz ou com uma cicatriz, aplicar uma dose; e com duas cicatrizes, não aplicar qualquer dose $e^{5,15}$.
Apesar da ausência de tendência significativa dos níveis de PGL-I com relação à diminuição ou aumento da idade, observou-se maior positividade nas faixas etárias abaixo dos 40 anos, resultado que mostrou uma maior tendência à soropositividade nas faixas mais jovens e consequente risco de adoecimento. $\bigcirc$ adoecimento em idade produtiva leva a óbvias perdas econômicas e problemas de ordem psicossocial, o que faz da hanseníase uma doença complexa, cuja importância ultrapassa os limites da saúde. Uma avaliação da situação da hanseníase, no estado do Pará, identificou que a maioria dos casos estava acontecendo nas faixas etárias mais jovens ${ }^{28}$.

Neste trabalho, foram encontrados alguns fatores de risco para o adoecimento por hanseníase entre os comunicantes intradomiciliares, destacando-se a baixa escolaridade e as condições de moradia ruins, além do contato com paciente MB. $O$ controle de hanseníase via comunicante amplia as chances de detecção precoce da doença com a minimização dos traumas sociais, psicológicos e demais conotações negativas a ela relacionados, além de reduzir a tendência de se lidar com a hanseníase somente durante o processo de adoecimento.

\section{CONCLUSÃO}

A baixa escolaridade e as condições de moradia insatisfatórias podem ser fatores de risco para o adoecimento por hanseníase para os comunicantes intradomiciliares. Entre esses, as faixas etárias mais jovens demonstram estar mais expostas ao contato com o bacilo da hanseníase. Houve prevalência de soropositividade no sexo feminino e entre comunicantes das formas de hanseníase $M B$, sendo mais prevalente quando utilizado o $P C=0,13$. É importante e necessário - seguimento desses grupos em áreas de elevada endemicidade em hanseníase, visando interromper a cadeia de transmissão da doença. Houve maior predominância de comunicantes com pelo menos uma dose vacinal de BCG, sendo orientada a imunização naqueles indivíduos sem sinais clínicos e laboratoriais de hanseníase. Como limitações do estudo, destacamos que o pequeno número amostral não permitiu resultados com significância estatística, em virtude da dificuldade encontrada no recrutamento dos contatos.

\section{AGRADECIMENTOS}

Aos funcionários e técnicos do Laboratório de Pesquisas em Dermatologia Tropical e Doenças Endêmicas do NMT/UFPA e do Laboratório de Hanseníase (Seção de Bacteriologia e Micologia/IEC).

\section{APOIO FINANCEIRO}

Programa Institucional de Bolsas de Iniciação Científica, Conselho Nacional de Desenvolvimento Científico e Tecnológico (PIBIC/CNPq/UFPA).

\section{CONTRIBUIÇÃO DOS AUTORES}

Maria Heliana Chaves Monteiro da Cunha: elaborou $\mathrm{o}$ projeto de comunicantes que deu 
origem ao artigo, tendo sido por ele responsável, e desenvolveu todos os passos da pesquisa; Maria do Perpétuo Socorro Amador Silvestre: realizou a sorologia e contribuiu na análise dos dados; Alison Ramos da Silva: participou da pesquisa de campo e realizou a estatística; Diana Domingas Silva do Rosário: realizou pesquisa de campo; Marília Brasil Xavier: contribuiu na discussão e revisão do texto.
Todos os autores contribuíram na concepção e delineamento do artigo, pesquisa de campo, análises estatísticas, discussão, redação e revisão crítica de seu conteúdo.

Todos os autores aprovaram a versão final do manuscrito e são responsáveis por todos os aspectos do trabalho, garantindo sua precisão e integridade.

\section{REFERÊNCIAS}

1 Ridley DS, Jopling WH. Classification of leprosy according to immunity: a five group system. Int J Lepr Other Mycobact Dis. 1966 JulSep;34(3):225-73.

2 Lombardi C. Hanseníase: epidemiologia e controle. São Paulo: Imprensa Oficial do Estado; 1990.

3 Ministério da Saúde (BR). Divisão Nacional de Dermatologia Sanitária. Controle da hanseníase em serviços básicos de saúde. In: $4^{\circ}$ Congresso Brasileiro de Hansenologia; 1982; Porto Alegre, Brasil. [Porto Alegre (RS): editora desconhecida]; 1982.

$46^{\circ}$ Congresso Internacional de Leprologia; 1953; Madrid, Espanha. Madrid (ES): Association de La Lepra; 1953.

5 Brasil. Ministério da Saúde. Gabinete do Ministro. Portaria $n^{\circ}$ 3.125, de 7 de outubro de 2010. Aprova as Diretrizes para vigilância, atenção e controle da hanseníase. Diário Oficial da União, Brasília (DF), 2010 out 15; Seção 1:55.

6 Ministério da Saúde (BR). Guia para o controle da hanseníase. Brasília: Ministério da Saúde; 2009.

7 Pinto Neto JM, Villa TCS, Mencaroni DA. Considerações epidemiológicas referentes ao controle dos comunicantes de hanseníase. Hansen Int. 2002 jan-jun;27(1):23-8.

8 Bührer SB, Smits HL, Gussenhoven GC, Van Ingen CW, Klatser PR. A simple dipstick assay for the detection of antibodies to phenolic glycolipid-I of Mycobacterium leprae. Am J Trop Med Hyg. 1998 Feb;58(2):133-6.

9 Bührer-Sékula S. Sorologia PGL-I na hanseníase. Rev Soc Bras Med Trop. 2008;41 supl 2:53-5.

10 Brett SJ, Payne SN, Gigg J, Draper SN. Analysis of the major antigenic determinants of the characteristic phenolic glycolipid from Mycobacterium leprae. Clin Exp Immunol. 1984 Apr;56(1):89-96.

11 Brito MFM, Ximenes RAA, Gallo MEN, BührerSékula S. Associação entre reação hansênica após alta e a carga bacilar avaliada utilizando sorologia anti PGL-1 e baciloscopia. Rev Soc Bras Med Trop. 2008;41 supl 2:67-72.
12 Cunha MHC, Silvestre MPSA, Queiroz MFA, Xavier MB. Perfil de anticorpos anti-PGL-1 em indivíduos sadios de áreas endêmicas para hanseníase do estado do Pará, Brasil. Rev Pan-Amaz Saude. 2012 jul-set;3(3):41-7.

13 Ayres M, Ayres MJ, Ayres DL, Santos AS. BioEstat 5.0: aplicações estatísticas nas áreas das ciências biológicas e médicas. Belém: Sociedade Civil Mamirauá: MCT - CNPq; 2007.

14 Vieira CSCA, Soares MT, Ribeiro CTSX, Silva LFG. Avaliação e controle de contatos faltosos de doentes com hanseníase. Rev Bras Enferm. 2008 nov;61 no esp:682-8.

15 Brasil. Ministério da Saúde. Portaria Conjunta $n^{\circ}$ 125, de 26 de março de 2009. Define ações de controle da hanseníase. Diário Oficial da União, Brasília (DF), 2009 Mar 27; Seção 1:73.

16 Talhari S, Neves RG. Dermatologia tropical: hanseníase. Manaus: Tropical; 1997.

17 Dessunti EM, Soubhia Z, Alves E, Aranda CM, Barro MPAA. Hanseníase: o controle dos contatos no município de Londrina-PR em um período de dez anos. Rev Bras Enferm. 2008 nov;61 no. esp:689-93.

18 Leite KKC, Costa JML, Aldina Barral, Caldas AJM, Corrêa RGCF, Aquino DMC. Perfil epidemiológico dos contatos de casos de hanseníase em área hiperendêmica na Amazônia do Maranhão. Cad Saude Coletiva. 2009;17(1):235-49.

19 Sousa LM, Maranhão LC, Pires CAA, Rodrigues DM. Conhecimento sobre hanseníase de contatos intradomiciliares na atenção primária em Ananindeua, Pará, Brasil. Rev Bras Med Fam Comunidade. 2013 jan-mar;8(26):20-3.

20 Banco Nacional de Desenvolvimento. Relatório anual 2014. Rio de Janeiro: BNDES; 2014.

21 Instituto Brasileiro de Geografia e Estatística. Indicadores mínimos de condições de vida no Brasil [Internet]. Rio de Janeiro: IBGE; 2016 [citado 2016 jan 26]. Disponível em: http:// www.ibge.gov.br/home/estatistica/populacao/ condicaodevida/indicadoresminimos/default_ minimos.shtmPyuhiouh. 
22 Lombardi C, Pedrazzani ES, Pedrazzani JC, Ferreira Filho P, Zicker F. Eficácia protetora del BCG contra lepra en São Paulo, Brasil. Bol Oficina Sanit Panam. 1995 nov;119(5):415-21.

23 Oliveira MLW, Cavaliére FAM, Maceira JMP, BührerSékula S. O uso da sorologia como ferramenta adicional no apoio ao diagnóstico de casos difíceis de hanseníase multibacilar: lições de uma unidade de referência. Rev Soc Bras Med Trop. 2008;41 supl 2:27-33.

24 Penna G, Pinto LF, Soranz D, Glatt R. High incidence of diseases endemic to the Amazon region of Brazil, 2001-2006. Emerg Infect Dis. 2009 Apr; 15(4):626-32.

25 Ministério da Saúde (BR). Departamento de Informática do SUS. Sistema de Informação de Agravos de Notificação. Hanseníase - Casos confirmados notificados no Sistema de Informação de Agravos de Notificação - Sinan Net [Internet]. Brasília: Ministério da Saúde; 2015 [citado 2015 out 21]. Disponível em: http://tabnet.datasus.gov.br/cgi/ tabcgi.exe? sinannet/hanseniase/cnv/hanswuf.def.
26 Salgado CG, Ferreira DVG, Frade MAC, Guimarães LS, Silva MB, Barreto JG. High antiphenolic glycolipid-I titers and hidden leprosy cases, Amazon region. Emerg Infect Dis. 2012 May; 18(5):889-90.

27 Menzel S, Harboe M, Bergsvik H, Brennan PJ. Antibodies to a synthetic analog of phenolic glycolipid-I of Mycobacterium leprae in healthy household contacts of patients with leprosy. Int J Lepr Other Mycobact Dis. 1987 Dec;55(4):617-25.

28 Palácios VRCM, Dias RS, Neves DCO. Estudo da situação da hanseníase no Estado do Pará. Rev Para Med; 2010 abr-jun;24(2):49-56.

Recebido em / Received: 11/3/2016 Aceito em / Accepted: 12/12/2016 